\title{
PENAMAAN MAKANAN BERBAHAN UBI DI MINANGKABAU
}

\author{
Silvia Fransiska ${ }^{1 *}$, Reniwati ${ }^{2}$ Lindawati $^{3}$ \\ silviafransiska600@gmail.com* \\ Fakultas Ilmu Budaya Universitas Andalas, 1,2,3
}

\begin{abstract}
ABSTRAK
Artikel ini membahas nama-nama serta asal penamaan makanan berbahan baku ubi di Minangkabau. Metode yang digunakan pada penyedian data adalah metode cakap. Teknik dasar yang digunakan adalah teknik pancing. Teknik lanjutannya yaitu teknik cakap semuka, teknik catat dan rekam. Metode yang digunakan dalam analisis data adalah metode padan referensial. Teknik dasar yang digunakan adalah Teknik Pilah Unsur Penentu (PUP), dengan Teknik Lanjutan Teknik Hubung Banding Membedakan (HBB). Hasil analisis data menggunakan metode penyajian formal dan informal. Hasil analis diperoleh tiga puluh empat nama makanan berbahan baku ubi di Minangkabau. Asal-usul penamaannya ditemukan yaitu peniruan bunyi, sifat khas, penemu atau pembuat, tempat asal, bahan, keserupaan, dan penamaan baru.
\end{abstract}

Kata kunci: Nama, Penamaan, Makanan, Ubi, Minangkabau

\section{THE NAMING OF SWEET POTATOES FOOD IN MINANGKABAU}

\begin{abstract}
This article discusses the names and names of foods made from sweet potatoes in Minangkabau. The method used in providing data is the proficient method. The basic technique used is the fishing technique. The advanced techniques are open-to-face techniques, note-taking and recording techniques. The method used in data analysis is the referential equivalent method. The results of data analysis used formal and informal presentation methods. The results of the analysis obtained thirty-four names of foods made from sweet potatoes in Minangkabau. The origins of the naming were found, namely sound imitation, distinctive characteristics, inventor or maker, place of origin, materials, similarities, and new names.
\end{abstract}

Keywords: Name, Naming, Food, Sweet Potato, Minangkabau

Jurnal Elektronik WACANA ETNIK - Vol 8 No 1 2019, (23 - 32) p ISSN 2089-8746, e ISSN 2302-7142

Submit: Februari 2019. Diterima: Maret 2019. Publikasi: April 2019. 


\section{PENGANTAR}

Makanan bagi kehidupan manusia sangatlah penting agar mereka bisa bertahan hidup. Makanan dapat berupa produk pangan yang siap hidang atau yang langsung dimakan. Ada berbagai macam jenis bahan baku salah satunya adalah ubi. Ubi dapat diolah menjadi berbagai bentuk olahan makanan seperti kue, gorengan, kerupuk, dan sebagainya. Contohnya, kue talam. Kue Talam adalah makanan yang terbuat dari ubi kayu dengan santan sehingga membentuk dua lapisan. Kue ini memilki rasa manis dengan teksturnya yang khas. Bahan utama dari kue ini yaitu parutan ubi kayu, tepung beras, tepung sagu, gula pasir, garam, dan santan kelapa.

Nama Kue Talam terbentuk dari dua leksem yaitu kue dan talam. Wadah yang digunakan untuk kue ini adalah talam. Kue dalam Kamus Besar Bahasa Indonesia adalah panganan yang dibuat dari bahan yang bermacam-macam, dapat dibuat dalam berbagai bentuk. Sementara itu, talam merupakan sebuah wadah yang tak berkaki. Karena wadah yang digunakan untuk kue talam ini adalah talam maka dari itu orang Minangkabau memberi nama makanan ini kue talam.

Peneliti memilih objek ini karena banyaknya makanan modern yang ada saat ini. Masyarakat lebih menyukai makanan yang bersifat instan dan tidak merepotkan, makanan instan membuatnya tidak terlalu sulit dan bisa dibeli dengan mudah. Berbeda dengan makanan tradisional yang berkemungkinan sedikit kesulitan untuk membuat dan membelinya. Hal ini disebabkan oleh berkurangnya pedagang yang menjual makanan tradisional ini.

Masyarakat khususnya kaum muda saat ini lebih menyukai makanan yang bersifat modern dan cepat saji misalnya, spaghetti, brownis, kebab, pizza, sosis dan sebagainya. Maka dari itu, sebelum makanan tradisional ini hilang dan tindak dikenal lagi oleh masyarakat. Peneliti berusaha untuk mendokumentasikan nama makanan berbahan baku ubi dan asal penamaannya ini agar nantinya bisa dikenal oleh generasi yang akan datang.

\section{KERANGKA TEORI DAN METODE}

Leksikologi adalah ilmu yang mengambil leksikon sebagai objek kajinnya (Chaer, 2007:3). Leksikologi, butir-butir leksikal suatu bahan dapat dikaji melalui asal-usulnya, bentuk dan pembentukannya, maknanya, penggunaannya, aspek bunyi, dan ejaannya, serta berbagai aspek lainnya. Ruang lingkup dari leksikologi ini adalah leksikon. Leksikon mempunyai tiga pengertian, yaitu yang pertama adalah komponen bahasa yang memuat semua informasi tentang makna dan pemakaian kata dalam bahasa, kedua adalah kekayaan kata yang dimiliki seorang pembicara, penulis, atau suatu bahasa; kosa kata; pembendaharan kata, dan ketiga adalah daftar kata yang disusun seperti kamus, tetapi dengan penjelasan yang singkat dan praktis (Kridalaksana, 2008: 142). Chaer (2007: 2) mendefenisikan bahwa merupakan sebuah istilah yang lazim digunakan untuk mewadahi konsep kumpulan leksem dari suatu bahasa, baik itu kumpulan bahasa secara keseluruhan ataupun secara sebagian.

Nama merupakan kata-kata yang menjadi label setiap makhluk, benda aktivitas, dan peristiwa didunia ini (Djajasudarma, 2009: 47). Chaer membagi latar belakang penamaan berdasarkan, (1) peniruan bunyi, (2) penyebutan bagian, (3) penyebutan sifat khas, (4) penemu atau pembuat, (5) tempat asal, (6) bahan, (7) keserupaan, (8) 
pemendekan, dan (9) penamaan baru. Menurut Sudaryat (2008: 59), penamaan dengan peniruan bunyi muncul jika kata atau ungkapan merupakan bunyi dari benda yang diacunya. Dalam bahasa indonesia ada sejumlah kata yang berbentuk sebagai hasil peniruan bunyi. Maksudnya nama-nama benda atau hal tersebut dibentuk berdasarkan bunyi dari benda tersebut atau suara yang ditimbulkan oleh benda tersebut (Chaer, 1995: 45). Misalnya makanan dakakdakak ubi ungu disebut Dakak-dakak karena bunyinya saat dimakan "kak-kak". Ada istilah pars pro toto yaitu gaya bahasa yang menyebutkan bagian dari suatu benda lain atau hal, padahal yang dimaksud adalah keseluruhan (Chaer, 1995:45). Misalnya kata kepala dalam kalimat setiap kepala menerima bantuan seribu rupiah, bukanlah dalam arti "kepala" itu saja, melainkan orangnya sebagai satu keutuhan.

Penyebutan sifat khas adalah penamaan sesuatu benda berdasarkan sifat yang khas yang ada pada benda (Chaer, 20013: 46). Dalam peristiwa ini terjadi transportasi makna dalam pemakaian kata sifat menjadi kata benda. Disini terjadi perkembangan, yaitu berupa ciri makna yang disebut kata sifat itu mendesak kata bendanya karena sifatnya yang amat menonjol tersebut. Banyak nama benda yang diberi nama berdasarkan nama penemunya, nama pabrik pembuatnya, atau nama dalam peristiwa sejarah (Chaer, 1995: 47). Nama-nama demikian disebut dengan istilah appelativa. Misalnya nama makanan kolak dalimo diberikan oleh pembuat dari makanan tersebut yang bersuku dalimo. Sejumlah nama benda dapat ditelusuri berasal dari tempat dan asal benda tersebut (Chaer, 1995: 48).

Sejumlah benda yang namanya diambil dari nama bahan pokok benda itu. Penamaan dalam hal ini berdasarkan bahan yang digunakan untuk membuat objek. Penamaan atas dasar bahan yang juga digunakan untuk membuat benda itu menarik untuk dicermati. Nama benda tersebut diambil dari nama bahan pokok benda itu (Chaer, 1995: 50). Penamaan keserupaan adalah penamaan suatu benda berdasarkan keserupaan suatu benda dengan benda lain (Sudaryat, 2008: 60). Dalam praktik berbahasa banyak kata yang digunakan secara metaforis. Artinya kata itu digunakan dalam suatu ujaran yang maknanya disamakan atau dibandingkan dengan makna leksikal dari kata itu (Chaer, 1995: 50). Misalnya nama makanan bola-bola ubi karena makanan ini memiliki bentuk yang serupa dengan bola- bola kecil. Menurut Chaer, (1995: 51) dalam perkembangan bahasa terakhir ini banyak kata-kata dalam bahasa Indonesia yang berbentuk sebagai hasil penggabungan unsur-unsur huruf awal atau suku kata dari beberapa kata yang digabungkan menjadi satu.

Metode yang digunakan pada saat penyedian data adalah metode cakap. Hal pertama yang peneliti lakukan adalah pergi ke lapangan. Di lapangan peneliti bertemu langsung dengan informan dan melakukan percakapan. Tahapan selanjutnya peneliti memancing informan untuk bercakap-cakap mengenai makanan yang terbuat dari ubi, serta asal-usul dari nama makanan ubi yang ada di daerah tersebut. Metode ini dijabarkan melalui teknik dasar yaitu teknik pancing. Teknik pancing digunakan untuk memancing informan agar bisa mendapatkan informasi dari informan terkait data yang akan diteliti yang sulit didapatkan secara terang- terangan. Teknik dasar ini memiliki teknik lanjutan, yaitu teknik cakap semuka, teknik catat dan rekam. Penerapan teknik cakap semuka peneliti bertemu langsung dengan informan. Peneliti dan informan bercakap semuka. Di dalam teknik catat, peneliti mencatat keterangan dari informan.Peneliti harus mencatat semua penjelasan dari informan karena berisikan data. Populasi yang diambil dalam penelitian ini adalah makanan berbahan baku ubi di Minangkabau. Sampelnya yaitu nama-nama makanan berbahan baku ubi yang ada di Bukittinggi, Payakumbuh, Padang, dan Sijunjung. 


\section{HASIL DAN PEMBAHASAN}

Makanan merupakan salah satu kebutuhan manusia untuk menjalani kehidupan yaitu untuk bertahan hidup. Makanan terbagi atas dua jenis yaitu makanan pokok dan makanan penunjang. Makanan pokok merupakan makanan yang biasa dikonsumsi setiap hari yaitu seperti nasi. Makanan penunjang ialah makanan yang tidak harus dikonsumsi setiap hari atau biasanya digunakan sebagai cemilan. Makanan-makanan yang dikonsumsi tersebut pastilah memiliki nama. Nama merupakan sesuatu yang sangat diperlukan untuk mengenal dan membedakan benda ataupun makanan tersebut. Makanan memiliki beberapa jenis bahan baku salah satunya adalah ubi. Pada analisis data ini dibahas mengenai nama-nama makanan ubi dalam bahasa Minangkabau.

Nama-nama makanan berbahan baku ubi tersebut dibahas asal- usul penamaannya. Pada setiap nama-nama makanan ubi, asal-usul penamaan dianalisis berdasarkan data yang didapatkan dari hasil wawancara kepada beberapa masyarakat di beberapa daerah di Minangkabau dan dihubungkan dengan makna yang dikutip dari kamus.

Nama makanan ubi yang berlatar belakang peniruan bunyi adalah dakak- dakak. Dakak-dakak merupakan jajanan khas Sumatera Barat yang telah tersebar hampir di seluruh wilayah di Sumatera Barat. Penghasil terbesar dakak-dakak yang paling terkenal di Sumatera Barat yaitu di Nagari Simabur. Simabur merupakan salah satu nagari di Kecamatan Pariangan, Kabupaten Tanah Datar, Provinsi Sumatera Barat. Nagari Simabur berdekatan dengan Batusangkar yang merupakan ibu kota dari Kabupaten Tanah Datar. Di Nagari Simabur ini dapat ditemui rumah produksi dakak-dakak yang sudah berdiri cukup lama. Nama dakak-dakak di beberapa daerah yaitu Bukittinggi, Padang dan Sijunjung menyebut makanan ini dengan nama yang sama yaitu dakak-dakak tetapi, berbeda dengan Payakumbuh makanan ini disebut dengan nama kue sarang. Diberi nama dakak-dakak oleh suara yang dihasilkan oleh makanan tersebut, yang apabila digigit makanan ini akan menghasilkan suatu bunyi. Dakak-dakak dalam Kamus Bahasa Minangkabau (Burhanuddin, 2009: 178) memiliki arti alat penghasil bunyi dekak dalam kombinasi musik. Maka dari itu Masyarakat Simabur, Batusangkar memberi nama makanan ini dakak-dakak. Karena makanan ini bahan bakunya adalah ubi jalar ungu, maka disebutlah dakak-dakak.

Nama makanan ubi yang berlatar belakang penyebutan sifat khas adalah karak kaliang. Karak kaliang memiliki rasa yang lezat, gurih, dan enak. Karena kelezatan rasanya inilah yang menyebabkan karak kaliang menjadi makanan favorit yang dicari dan disukai oleh masyarakat Minangkabau. Tidak hanya di Minangkabau, karak kaliang juga dicari dan disukai oleh wisatawan dari luar daerah. Kerupuk karak kaliang biasanya dijadikan oleh-oleh saat berkunjung ke Minangkabau oleh wisatawan. Hampir di seluruh daerah di Minangkabau menyebut makanan ini dengan nama karak kaliang, yaitu daerah Bukittinggi, Payakumbuh, Sijunjung dan nama lapan-lapan oleh orang Padang. Disebut Karak Kaliang karena penyebutan sifat khas yaitu kata kaliang yang berarti sebutan untuk orang india yang berkulit hitam. Kerak dalam bahasa Minangkabau diucapkan karak. Kerak dalam Kamus Besar Bahasa Indonesia (Alwi dkk, 2007: 548) adalah lapisan yang kering (keras) atau hangus pada benda lain. Keling dalam bahasa Minangkabau diucapkan kaliang. Keling dalam Kamus Besar Bahasa Indonesia (Alwi dkk, 2007: 533) yaitu, orang berkulit hitam yang berasal dari India sebelah selatan. 
Pemberian nama karak kaliang menurut sumber yang didapatkan di lapangan, nama Karak Kaliang berasal dari seorang pembeli yang mendapat oleh- oleh dari penjual bumbu-bumbu siap saji di pasar Bukittinggi. Pedagang tersebut merupakan keturunan India yang berkulit hitam. Oleh-oleh tersebut adalah makanan yang mirip sekali dengan karak kaliang yang kita kenal saat ini. Pembeli itu memberi nama makanan tersebut dengan nama karak kaliang karena makanan tersebut didapat dari orang India yang berkulit hitam. Penambahan kata karak di awal kata kaliang disebabkan oleh pembeli ini berpendapat bahwa karak itu identik dengan hitam atau hangus.

Nama makanan ubi berlatar belakang penemu atau pembuat adalah kolak dalimo. Kolak dalimo merupakan salah satu makanan berbahan baku ubi kayu yang telah diolah menjadi tepung, dibuat menjadi bahan makanan berbentuk segi empat kecil berwarna merah dan putih lalu dimasak dengan cara dijadikan kolak. Dalimo ini biasanya bisa dijual di pasar maupun di warung. Dalimo bisa dibuat sendiri di rumah begitupun dengan kolaknya bisa juga dibuat di rumah. Kolak dalimo ini biasanya menjadi salah satu menu berbuka puasa pada saat bulan ramadhan. Makanan ini telah dikenal di seluruh daerah di Minangkabau umumnya dengan nama yang sama kolak dalimo, yaitu pada daerah Bukittinggi, Padang, Sijunjung dan konji dalimo oleh orang Payakumbuh. Penamaan makanan ini ditentukan dari dua bentuk yaitu penemu atau pembuat. Penemu atau pembuat makanan ini bersuku Dalimo. Pembuat memberi nama makanan ini dalimo sesuai dengan nama suku mereka Dalimo. Dalimo dalam Kamus Bahasa Minangkabau-Indonesia Balai Bahasa Padang (Burhanuddin, 2009: 181) berarti, nama salah satu suku di Minangkabau. Penambahan kata kolak dikarenakan makanan dibuat menjadi kolak. Karena bahan bakunya dalimo, maka nama makanan ini menjadi kolak dalimo.

Nama-nama makanan ubi yang berlatar belakang tempat asal adalah karupuak sanjai dan karupuak kamang. Karupuak sanjai adalah salah satu makanan khas Minangkabau yang jadi favorit oleh wisatawan dari daerah luar Minangkabau. Karupuak sanjai biasanya dijadikan oleh-oleh untuk dibawa pulang oleh wisatawan yang datang ke Minangkabau. Karupuak sanjai tersebar hampir di seluruh wilayah di Minangkabau. Di beberapa daerah di Minangkabau menyebut makanan ini dengan nama yang sama karupuak sanjai, yaitu pada daerah Bukittinggi, Padang, Sijunjung dan Payakumbuh. Pemberian nama karupuak sanjai ini berdasar nama tempat asal pembuatan makanan ini yaitu daerah Sanjai, desa yang berada dekat kota Bukittinggi. Karupuak diartikan ke bahasa Indonesia yaitu kerupuk. Kerupuk dalam Kamus Besar Bahasa Indonesia (Alwi dkk, 2007: 558 ) adalah makanan yang dibuat dari adonan tepung dicampur dengan lumatan udang atau ikan, setelah itu dikukus disayat-sayat tipis atau dibentuk dengan alat cetak jemur agar mudah digoreng. Sanjai dalam Kamus Lengkap Bahasa Minang (Saydam, 2002: 339) adalah nama desa dekat kota Bukittinggi, yang terkenal dengan kerupuk singkongnya. Karena makanan ini berasal dari daerah Sanjai maka orang Sanjai tersebut menamakan makanan ini dengan nama karupuak sanjai.

Karupuak kamang berasal dari Bukittinggi/Agam yaitu di Nagari Kamang Magek. Dahulu masyarakat di Nagari Kamang Magek lebih banyak yang berprofesi sebagai pengrajin karupuak kamang, namun pada saat sekarang ini Karupuak Kamang telah banyak diproduksi oleh banyak nagari di luar Kamang Magek, seperti Nagari Koto Tangah dan Kecamatan lain di Kabupaten Agam sehingga menyebabkan berkurangnya pengrajin karupuak kamang di Nagari Kamang Magek ini. Karupuak kamang memiliki rasa yang khas dibandingkan produksi kerupuk yang hampir sama dengan karupuak kamang di tempat lain dan diakui oleh banyak orang lebih gurih, renyah dan enak. Karupuak kamang 
sampai saat ini masih dijual di pasar-pasar tradisional, warung dan sebagainya. Di beberapa daerah lain di Minangkabau selain Bukittinggi juga memproduksi kerupuk yang sama dengan karupuak kamang ini dengan nama yang berbeda yaitu karupuak ubi, karupuak kuah, karupuak parancih, karupuak bunta, karupuak salo dan karupuak padang tarok atau karupuak piladang.

Penamaan makanan ubi berlatar belakang bahan adalah lapek ubi, paragede ubi, dan putu ubi. Lapek ubi adalah makanan yang terbuat dari ubi kayu yang memiliki warna kecoklat-coklatan dan dibungkus daun pisang. Lapek ubi dikenal hampir di seluruh wilayah Minangkabau dan beberapa daerah di Indonesia. Di beberapa daerah yang ada di Minangkabau menyebut makanan ini dengan nama lapek ubi dan ada di beberapa daerah seperti Sijunjung menyebut makanan ini dengan nama lopek ubi dan di Pariaman disebut dengan lapek parancih. Lapek dalam Kamus Bahasa Minangkabau Balai Bahasa padang (Burhanuddin, 2009: 470) adalah kue yang dibungkus daun pisang. Ubi dalam Kamus Bahasa Minangkabau-Indonesia Balai Bahasa Padang (Burhanuddin, 2009: 853) adalah umbi atau akar dari berbagai macam tumbuhan yang biasanya dapat dimakan. Jadi, lapek ubi berarti ubi yang diolah menjadi makanan yang disebut dengan lapek.

Paragede ubi adalah makanan berbahan baku ubi kayu yang berbentuk bulat dan berwarna kekuningkuningan. Paragede ubi ini dikenal di beberapa dearah di Indonesia dengan sebutan perkedel. Di Minangkabau perkedel ini dikenal dengan sebutan paragede. Di beberapa daerah di Minangkabau, yaitu Payakumbuh, Bukittinggi, Padang, dan Sijunjung menyebut makanan ini dengan nama yang sama, yaitu paragede ubi. Perkedel dalam Kamus Besar Bahasa Indonesia (Alwi dkk, 2007: 861) makanan yang dibuat dari kentang goreng atau rebus yang dihaluskan, dicampur dengan daging giling diberi bumbu merica, bawang putih, garam halus, kemudian dibentuk bundar-bundar pipih, dilumuri putih telur dan digoreng. Ubi dalam Kamus Bahasa Minangkabau-Indonesia Balai Bahasa Padang (Burhanuddin, 2009: 853) adalah umbi atau akar dari berbagai macam tumbuhan yang biasanya dapat dimakan. Jadi nama paragede ubi berarti dari bahan baku yang digunakan untuk membuat makanan ini karena jenis bahan baku dari perkedel ini bermacam-macam salah satunya adalah ubi. Maka dari itu, orang Minangkabau menyebut makanan ini dengan nama paragede ubi karena terbuat dari ubi.

Putu ubi memiliki keunikan pada cara memasaknya, yaitu singkong diparut, air parutannya dibuang, parutan singkong diambil sebanyak dua sendok lalu diletakkan pada tambikar. Pada bagian tengahnya dicampurkan kelapa, kacang dan gula. Makanan ini hanya dikenal di beberapa daerah di Minangkabau dan menyebut makanan ini dengan nama putu ubi. Penamaan putu ubi dilatarbelakangi oleh bahan dari membuat makanan ini yaitu ubi. Putu dalam Kamus Bahasa Minangkabau-Indonesia Balai Bahasa Padang (Burhanuddin, 2009: 649) adalah nama panganan, dibuat dari tepung beras yang ditengahnya diberi gula merah, dimakan dengan kelapa parut. Ubi umbi atau akar dari berbagai macam tumbuhan yang biasanya dapat dimakan. Jadi, nama putu ubi berarti ubi yang diolah menjadi makanan yang disebut dengan putu.

Penamaan makanan ubi berlatar belakang keserupaan yaitu bola-bola ubi, godok batinta, karupuak acik/racik, karupuak cancang, karupuak laweh, karupuak tunjua, kue talam, sarang balam, dan serundeng ubi. Bolabola Ubi adalah makanan yang terbuat dari ubi jalar ungu yang berbentuk bulat seperti bola. Bola-bola ubi merupakan makanan yang baru dikenal oleh masyarakat Minangkabau. Bola-bola ubi ini merupakan makanan yang mudah 
ditemui di warung ataupun pedagang yang menjual gorengan. Bola-bola ubi ini dapat ditemukan dibeberapa derah di Minangkabau dengan nama yang sama. Pemberian nama Bola-bola ubi oleh karena bentuknya yang menyerupai bolabola berukuran kecil. Karena bentuknya yang menyerupai bola, maka orang Minangkabau menyebut makanan ini dengan nama Bola-bola ubi.

Godok tinta mempunyai dua versi bahan baku untuk membuatnya, bahan baku yang sering digunakan untuk membuat godok tinta adalah pisang. Namun sebagian orang menggunakan ubi kayu untuk membuat godok tinta ini. Meskipun bahan dasarnya berbeda, tetapi bentuk makanan ini tetap sama, namun dengan rasa yang berbeda. Godok inta memang sudah jarang ditemui pada saat sekarang ini, tetapi apabila pada bulan ramadhan makanan ini mudah sekali untuk ditemui karena godok tinta merupakan jajananan favorit masyarakat untuk berbuka puasa. Makanan ini dikenal dibeberapa daerah di Minangkabau dengan nama yang berbeda, yaitu di daerah Padang menyebut makanan ini Paruik ayam, di Sijunjung makanan ini dikenal dengan nama godok cinta, daerah Payakumbuh menyebut makanan ini dengan nama godok tinta, dan di daerah Bukittinggi menyebut makanan ini godok batinta. Disebut godok tinta karena bentuk dari makanan ini, godok bentuknya agak bulat dan dilumuri dengan gula aren apabila dicairkan menyerupai tinta. Godok dalam Kamus Bahasa Minangkabau-Indonesia Balai Bahasa Padang (Burhanuddin, 2009: 380) adalah makanan yang terbuat dari tepung (beras, ubi, dsb). Sementara itu tinta dalam Kamus Besar Bahasa Indonesia (Alwi dkk, 2007: 1198) merupakan barang cair yang berwarna (hitam, merah dsb) untuk menulis. Karena warna dari lapisan luar makanan ini bewarna agak kemerah-merahan karena ditaburi gula aren sehingga berbentuk seperti taburan tinta, maka dari itu orang Minangkabau memberi nama makan tersebut godok tinta.

Goreang tongkang memiliki banyak khasiat dan manfaat karena goreng tongkang ini terbuat dari ubi yang mempunyai banyak khasiat dan manfaat bagi tubuh. Goreang tongkang ini dimakan pada saat santai dan bisa dibuat sendiri di rumah. Goreang tongkang dikenal dibeberapa daerah di Minangkabau dengan nama yang sama. Disebut Goreang tongkang karena keserupaan makanan ini dengan perahu tongkang yang digunakan untuk mengangkut barang. Perahu tongkang keseluruhan dari bahan membuat perahunya adalah besi yang keras. Tongkang dalam Kamus Besar Bahasa Indonesia (Alwi ddk, 2007: 1205) adalah perahu yang agak besar (untuk mengangkut barang dan sebagainya). Karena makanan ini menyerupai perahu tongkang tersebut, maka orang Minangkabau memberi makanan ini nama goreang tongkang karena bentuk dan rasanya yang keras menyerupai perahu tongkang.

Karupuak acik/racik adalah makanan yang biasanya di gunakan sebagai lauk untuk dimakan dengan nasi. Karupuak acik/racik ini mudah ditemukan di pasar-pasar tradisional yang ada di Minangkabau. Makanan ini sudah dikenal hampir diseluruh daerah di Minangkabau. Makanan ini biasanya dijadikan sebagai hidangan untuk acara pernikahan maupun acara adat lainnya dibeberapa daerah di Minangkabau. Nama karupuak acik/racik ini oleh karena bentuk dari kerupuk ini yaitu berbentuk tipis-tipis memanjang. Karena cara pembuatannya kerupuk ini yang diracik tipis-tipis, maka makanan ini diberi nama karupuak acik/racik.

Karupuak cancang merupakan salah satu makanan yang dijadikan oleh- oleh bagi wisatawan yang datang dari luar daerah. Karupuak cancang ini sudah dikenal hampir di seluruh daerah di Minangkabau dan diperjual belikan di pasar- pasar tradisional, warung dan mini market. Nama makanan ini disebagian daerah di Minangkabau memiliki nama yang sama. Namun di beberapa daerah juga ada yang menyebutnya dengan sebutan nama lain yaitu dakak- 
dakak, karupuak dadu, ganepo dan karupuak ampera. Nama karupuak cancang berdasarkan bentuk makanan yaitu dipotong kecil-kecil dengan cara dicencang. Cencang dalam bahasa Minangkabau diucapkan cancang. Cencang dalam Kamus Besar Bahasa Indonesia (Alwi dkk, 2007: 205) berarti potong kecil-kecil (halus-halus). Jadi pemberian nama karupuak cancang ini berasal dari bentuk makanan ini yang di potong dengan cara dicencang kecil-kecil dan penambahan kata karupuak karena makanan ini merupakan sejenis kerupuk dan dalam bahasa Minang disebut karupuak.

Karupuak laweh adalah kerupuk mentah yang berbentuk lingkaran berukuran besar. Makanan ini dikenal hampir seluruh daerah di Minangkabau dengan nama yang sama dan ada yang berbeda, di daerah Bukittinggi dan Padang menyebut makanan ini dengan nama yang sama, yaitu karupuak laweh dan dengan nama yang berbeda di daerah Payakumbuh dengan nama karupuak ubi dan di Sijunjung dengan nama karupuak gambok. Pemberian nama karupuak laweh ini oleh karena bentuk dari makanan tersebut yaitu laweh 'luas'. Luas dalam bahasa Minangkabau diucapkan laweh. Luas dalam Kamus Besar Bahasa Indonesia (Alwi dkk, 2007: 685) lapang, lebar. penambahan kata karupuak sebelum kata laweh karena makanan ini merupakan sejenis kerupuk. Karena bentuk keripiknya yang lebar maka dari itu orang Minangkabau memberi nama makanan ini karupuak laweh. Jadi, nama Karupuak Laweh berarti kerupuk yang berukuran luas. Maka dari itu, orang Minangkabau memberi nama makanan ini karupuak laweh karena bentuknya yang luas.

Karupuak tunjuak digunakan sebagai makanan yang wajib disajikan pada saat acara pernikahan atau baralek oleh orang Nagari Kamang, Kabupaten Agam. Karupuak tunjuak paling mudah ditemukan di Bukittingi. Tetapi, di tempat lain masih bisa ditemukan karena makanan ini beredar dibeberapa daerah di Minangkabau. Nama karupuak tunjuak ini ditemukan di Bukittinggi. Di daerah Payakumbuh makanan ini disebut dengan nama sayiang gajah. Pemberian nama karupuak tunjuak juga oleh karena bentuk yaitu seperti jari telunjuk. Telunjuk dalam bahasa Minangkabau diucapkan tunjuak. Telunjuk dalam Kamus Besar Bahasa Indonesia (Alwi dkk, 2007: 1163) yaitu jari tangan antara jari tengah dan ibu jari yang biasa digunakan untuk menunjuk dan penambahan kata karupuak karena makanan ini merupakan sejenis kerupuk, dalam bahasa Minangkabau diucapkan karupuak. Karena bentuknya yang menyerupai jari telunjuk, maka orang Minangkabau menyebut makanan ini dengan nama karupuak tunjuak.

Kue talam merupakan makanan khas asli Sumatera Barat yang telah dikenal semenjak tahun 1980-an. Pada saat itu kue talam merupakan jajanan favorit khas anak-anak sekolah. Namun, seiring perkembangan zaman makanan ini sudah jarang ditemukan dan jarang diperjual belikan di pasar maupun di warung, tetapi masih ada beberapa daerah di Minangkabau yang masih membuat dan memperjual belikan makanan ini dan ada juga yang membuat kue talam ini hanya pada acara penting saja. Nama makanan ini hampir seluruh masyarakat di Minangkabau menyebutnya dengan nama kue talam. Nama kue talam terbentuk dari dua leksem yaitu kue dan talam. Wadah yang digunakan untuk kue ini adalah talam. Kue dalam Kamus Besar Bahasa Indonesia (Alwi dkk, 2007: 608) adalah panganan yang dibuat dari bahan yang bermacam-macam, dapat dibuat dalam berbagai bentuk. Talam dalam Kamus Besar Bahasa Indonesia (Alwi dkk, 2007: 1126) merupakan sebuah dulang yang tak berkaki. Karena wadah yang digunakan untuk kue talam ini adalah talam, maka dari itu, orang Minangkabau memberi nama makanan ini kue talam.

Jurnal Elektronik WACANA ETNIK - Vol 8 No 1 2019, (23 - 32) p ISSN 2089-8746, e ISSN 2302-7142 
Sarang balam merupakan salah satu makanan yang dijadikan oleh-oleh untuk dibawa pulang oleh wisatawan. Makanan ini di produksi di Batusangkar dan tersebar dibeberapa daerah di Minangkabau. Nama makanan ini di beberapa daerah di Minangkabau menyebut makanan ini dengan nama yang sama yaitu sarang balam, misalnya saja pada daerah Bukittinggi, padang, dan Sijunjung meneyebut makanan ini dengan nama sarang balam dan pada daerah Payakumbuh dengan nama yang berbeda, yaitu karabu soga. Nama sarang balam berdasar pada bentuk makanan tersebut yang memiliki bentuk menyerupai sarang burung yaitu burung balam. Sarang dalam Kamus Besar Bahasa Indonesia (Alwi dkk, 2007: 999) adalah tempat yang dibuat atau yang dipilih oleh binatang atau unggas, seperti burung untuk bertelur dan memiara anaknya. Balam dalam Kamus Besar Bahasa Indonesia (Alwi dkk, 2007: 96) adalah burung terukur (di jawa disebut direkuku). Jadi, nama sarang balam berarti diambil dari bentuk makanan yang menyerupai sarang burung yaitu burung balam. Maka dari itu, orang minangkabau memberi nama makanan ini sarang balam.

Serundeng merupakan makanan berbahan baku ubi jalar yang dapat ditemukan di pasar-pasar tradisional, warung, toko pusat oleh-oleh dan mini market. Serundeng dikenal hampir di seluruh daerah di Minangkabau dengan nama yang sama dan ada juga yang berbeda. Pemberian nama serundeng dilatarbelakangi oleh bentuk makanan ini yang serupa atau mirip dengan serundeng yang terbuat dari parutan kelapa yang digoreng ditambahkan bumbu-bumbu halus, seperti bawang merah, bawang putih, dan gula. Karena bentuk dan warnanya sangat mirip dengan serundeng kelapa, maka orang Minangkabau menyebut makanan ini serundeng.

\section{PENUTUP}

Makanan merupakan salah satu kebutuhan manusia untuk menjalani kehidupan yaitu untuk bertahan hidup. Makanan terbagi atas dua jenis yaitu makanan pokok dan makanan penunjang. Makanan pokok merupakan makanan yang biasa dikonsumsi setiap hari yaitu seperti nasi. Makanan penunjang ialah makanan yang tidak harus dikonsumsi setiap hari atau biasanya digunakan sebagai cemilan. Makanan-makanan yang dikonsumsi tersebut pastilah memiliki nama. Nama merupakan sesuatu yang sangat diperlukan untuk mengenal dan membedakan benda ataupun makanan tersebut.

\section{REFERENSI}

Alwi, Hasan dkk. 2007. Kamus Besar Bahasa Indonesia. Jakarta: Balai Pustaka.

Baehaqie. 2007, Semiotis Nama-Nama Makanan dalam Sesaji Selamatan Tingkeban di Dukuh Palem. Artikel. Yogyakarta. Pascasarjana Universitas Gadjah Mada.

Burhanuddin, Erwina dkk. 2009. Kamus Bahasa Minangkabau-Indonesia Balai Pustaka Padang. Pusat Bahasa Departemen Pendidikan Nasional.

Chaer, Abdul. 2007. Leksikologi \& Leksikografi Indonesia. Jakarta: Rineka Cipta. 2002. Pengantar Semantik Bahasa Indonesia. Jakarta: Rineka Cipta.

Chaer, Abdul. 2003. Linguistik umum. Jakarta: Rineka Cipta.

Djajasudarman, Fatimah. 1993. Semantik 1 Pengantar Kearah Ilmu Makna. Bandung: PT Eresco anggota IKAPI.

Kridalaksana, Harimurti. 1986. Kelas Kata dalam Bahasa Indonesia. Jakarta: Gramedia. 2008. Kamus Linguistik. Jakarta: Gramedia.

Kridalaksana, Harimurti. 2007. Pembentukan Kata dalam Bahasa Indonesia. Jakarta: Gramedia.

Mahsun. 2005. Metode Penelitian Bahasa. Jakarta : PT RajaGrafindo Persada. 
Pateda, Mansoer. 2011. Linguistik (Sebuah Pengantar). Bandung : Angkasa.

Ramlan. 2012. Morfologi Suatu Tinjauan Deskriptif. Yogyakarta : C.V. Karyono

Rukmana, R. 2002. Ubi kayu : Budidaya dan Pasca Panen. Yogyakarta : Kanisius Santoso, Riyaldi. 2003. Semiotika Sosial: Pandangan Terhadap Bahasa. Surabaya: Pustaka Eureka.

Setiapani. 2015. Fenomena penggunaan nama-nama unik pada makanan di bandung : kajian semantik kognitif. Bandung. Fakultas Bahasa dan Sastra Universitas Pendidikan Indonesia.

Sudaryanto. 1993. Metode dan aneka teknik analisis bahasa. Yogyakarta: Duta Wacana University Press.

Sudaryanto. 1986. Metode Linguistik: Bagian Pertama ke Arah Memahami Metode Linguistik. Yogykarta : Gajah Mada University Press.

Sudaryat, Yayat, 2009. Makna dalam Wacana. Bandung : CV. Yrama Widya. 